\title{
Factors affecting the lifetime of plastic -coated sheets
}

\author{
Jozef Kmec ${ }^{1}$, Erika Fechová ${ }^{2}$, Stella Hrehová ${ }^{3}$ \\ jozef.kmec@unipo.sk ${ }^{1}$,efechova@gmail.com² ${ }^{2}$,stella.hrehova@tuke.sk ${ }^{3}$
}

\begin{abstract}
${ }^{1}$ University of Prešov in Prešov, Faculty of Humanities and Natural Sciences, Department of Physics, Mathematics and Techniques, Ul. 17 novembra č. 1, Prešov, 080 01, Slovakia ${ }^{2}$ Technical University of Košice, Faculty of Manufacturing Technologies with a seat in Prešov, Department of Natural Sciences and Humanities, Bayerova 1, 08001 Prešov, Slovakia

${ }^{3}$ Technical University of Košice, Faculty of Manufacturing Technologies with a seat in Prešov, Department of Industrial Engineering and Informatics, Bayerova 1, 08001 Prešov, Slovakia
\end{abstract}

\begin{abstract}
The paper deals with factors obtained by corrosion test in a salt spray chamber at plastic-coated sheets, which are used in various areas of economy, e.g. automotive industry, construction etc. The goal of the experiment was to find out the relation between input parameters ( $\mathrm{Zn}$ layer, Top+primer, Backoat) and output parameter. The experiment was planned with the use of full factorial design. Evaluation of experimental results was processed by means of Minitab 16 statistical software.
\end{abstract}

Keywords:plastic-coated sheets, test in salt spray chamber, corroding time

\section{Introduction}

In the area of technologies and utilization of construction materials the special emphasis is put on knowledge of mechanical, electric, chemical, but also magnetic properties of materials depending of their structure. Deterioration of materials by chemical or physical and chemical effects of environment is becoming more and more serious problem. Natural corrosion environments (atmosphere or water) are polluted by industrial activities and pollution causes that their aggression is rising. At the same time requirements for reliability and no-failure operation of materials are increasing, because disruption to their functions can have serious consequences in wide range of various areas of economy. To secure the longest possible durability life of products it is necessary to protect them from unwanted influences of environment, which become evident on the surface in the form of corrosion. Zinc coated sheets are long attested materials mainly at production of trapezoidal and corrugated sheets, folding roof covering, sheet covering of roofs, windows and last but not least in automotive industry. Undeniable advantage of zinc coated sheets is their low price. Big disadvantage is their low durability and currently low aesthetic value [1], 
[2], [3], [4]. Another degree of surface treatment of cold-rolled zinc coated sheets is plastic-coated surface treatment [5].

Plastic-coated material consists of metallic core - substratum - with continually spread layers of paint. Coated plastics is a product of synergic combination of metallic substratum, metallic coat, chemical pre-treatment and usually 2, 3 or 4-layer paint (Figure 1) [6].

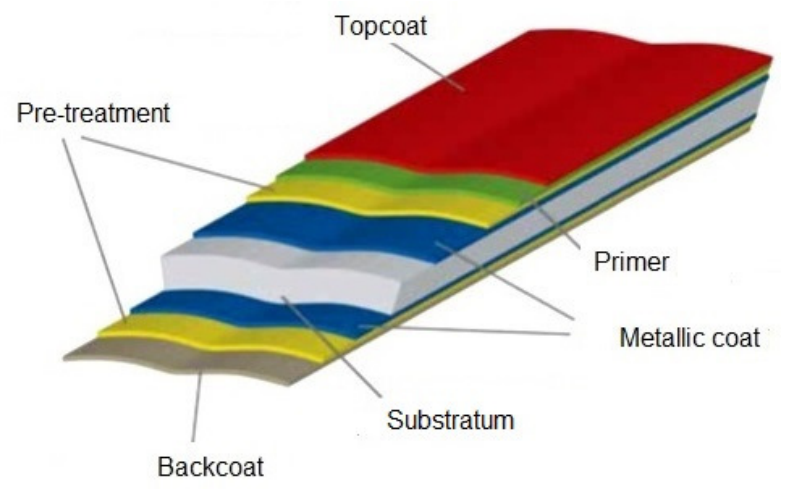

Fig. 1. Typical composition of plastic-coated product.

Primer substratum forms the basic part of the product. Majority of plastic-coated products uses steel or aluminium, but also other metals can be used such as copper or zinc, which can give the substratum higher hardness, improved formation or different resistance against corrosion. Majority of plastic-coated products uses steel substratum with additional metal coat, which improves corrosion resistance of steel. The most commonly used metal coat for steel is zinc layer. There are several variants available - it is most frequently zinc dipped coat. Recently it has been also zinc alloys with addition of magnesium and aluminium.Pre-treatment is a thin layer (to $1 \mu \mathrm{m}$ ) of chemical compound spread on cleansed and dried substratum before single paint coat. Pre-treatment provides compatibility between substratum and paints. It ensures optimal adhesion of paints and subsequently corrosion resistance of plasticcoated sheet. Primer is a basic paint spread on pre-treated substratum either on upper side or on both sides. It secures good corrosion resistance. Topcoat is on the upper side or on both sides of the steel sheet. It gives characteristic look to the product. It determines flexibility, resistance and durability of the product. Backcoat is on the bottom side of the steel sheet. The combination of individual layers secures final properties of plastic-coated products (Figure 2).

In general plastic-coated product is designed according to the topcoat type. The coat thickness is traditionally referred to as a combination of thickness of topcoat and primer. The basic coat is in most cases the thin layer with thickness of $5 \mu \mathrm{m}$ and major part of the coat is created by topcoat. There are three main categories of paints: liquid paint, film (laminate) and powder paint. More than $90 \%$ plasticcoated products use liquid paints. 


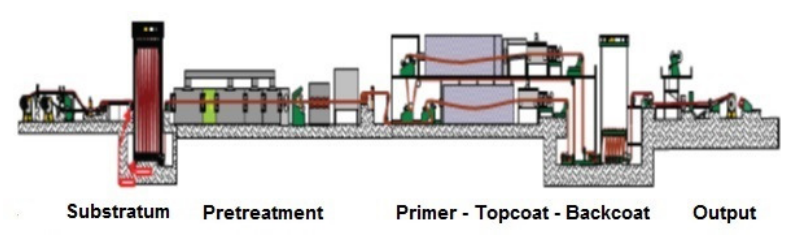

Fig. 2. Scheme of spreading coats on production line.

Very good formability, chemical resistance, reflectivity or emissivity, resistance against UV radiation and corrosion resistance belong to important properties and characteristics of plastic coats. The main advantages of use of plastic coats are mainly their durability, corrosion resistance, long-term kept aesthetic look, 100\% recycling at the end of their lifetime, maintenance or need of change is minimal or completely eliminated.

Table 1 contains coating types, their terminology and thickness of their applied layers. Coloured shade of coatings is prescribed according to the International Colour Code RAL. Other coloured shades are possible after they are agreed.

Table 1. Coating types.

\begin{tabular}{|l|l|}
\hline Bottom coating - BACKOAT & thickness of $10 \mu \mathrm{m}$ \\
\hline Basic coating - PRIMER & thickness of $5 \mu \mathrm{m}$ \\
\hline Top coating - TOPCOAT & thickness of $25 \mu \mathrm{m}$ \\
\hline POLYESTER (PES) & applications inside and outside, industry [1] \\
\hline $\begin{array}{l}\text { POLYVINYLDENFLUORIDE } \\
\text { (PVDF) }\end{array}$ & $\begin{array}{l}\text { good resistance against corrosion, abrasion, } \\
\text { chemicals }\end{array}$ \\
\hline
\end{tabular}

\section{$2 \quad$ Experimental}

\subsection{Setting up the corrosion test by salt spray and principle of the method}

To set up the corrosion test by salt spray the international norm STN EN ISO 9227:2012 [7] was used. The norm specifies device, tannins and test procedures in neutral salt spray (NSS), salt spray acidified by acetic acid (AASS) and salt spray acidified by acetic acid that is accelerated by copper (CASS) to assess the resistance against corrosion of metallic materials with permanent or temporal protection against corrosion and without it [6]. Tested sample is exposed to effects of sprayed salt spray for predetermined time. Possible occurrence of corrosion expressed by the degree of coating crack and degree of pustule formation is evaluated. The method describes possible process for testing resistance of materials with organic coating by effect of salt spray. Tests are carried out in a condensation chamber, where required environment can be prepared. Construction of the condensation chamber allows to change and keep conditions of the test, temperature and relative humidity by means of heater element and water bath of the corrosion chamber. Environment we used was created by sodium chloride $(\mathrm{NaCl})$, distilled water and sodium carbonate $\left(\mathrm{Na}_{2} \mathrm{CO}_{3}\right)$. The samples of plastic-coated sheets with dimensions of 
$200 \mathrm{~mm} \times 150 \mathrm{~mm}$ were used to measure corroding time in the salt chamber. Dimension of $200 \mathrm{~mm}$ of panel sheet must be equal to the direction of rolling. Two cuts $40 \mathrm{~mm}$ long $90^{\circ}$ angle-wise were made on the sample. Lower cut must head for horizontal central point and must be $50 \mathrm{~mm}$ distant from it. Vertical cut must be $60 \mathrm{~mm}$ distant from lower edge. $90^{\circ}$ variable bend radius, which is parallel to the left edge (that is $200 \mathrm{~mm}$ long) and $25 \mathrm{~mm}$ distant from the left edge, was made. Variable bend radius is given by bend in the interval $\langle 1 T, 3 T\rangle$, where $T$ is width of bent part of the sample.

Salt chamber CONSTASAL S 1000M was used for measurement. Its description, maintenance, calibration and its technical parameters are described in work regulations for operation of the device. Cutting tool with a solid steel spike was used to create a cut. The cut needs to have extension cross part, which reveals foundation metal that is approximately $1 \mathrm{~mm}$ wide (according to Clemen) (Figure 3). Indentation must show the profile of $\mathrm{V}$ shape and must reveal at least $0,2 \mathrm{~mm}$ of metal back coat. The suitable shape of layout tools is a solid metal spike with radius approximately of $0,5 \mathrm{~mm}$ (van Laar). Clear self-adhesive tape was $25 \mathrm{~mm}$ wide with $(10 \pm 1) \mathrm{N}$ adhesion on $25 \mathrm{~mm}$ width according to IEC 60454-2.

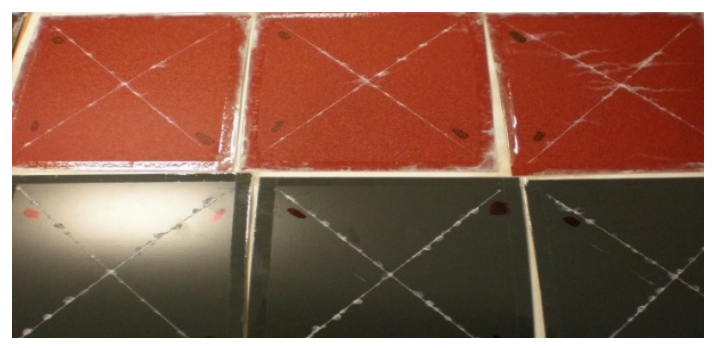

Fig. 3. Stress-corrosion cracking.

\subsection{Measuring procedure in the salt chamber}

1. $5 \%$ salt solution was prepared $(1 \mathrm{~kg} \mathrm{NaCl}$ is dissolved in 20 litres of distilled water), $\mathrm{pH}$ of prepared solution must be in the interval $6-7$.

2. Tank of the salt chamber was filled by salt solution.

3. Carriers with samples were placed into the salt chamber. The samples should not be placed above a jet and a diffusion cone.

4. Main switch was pressed to launch the test. Key shift with zero position was switched to spraying.

5. Indicator light of function of heating of the testing chamber SAL and indicator light of function of heating of humidifier were lit up. Indicator lights were switched off, when optimal temperatures (temperature of $35^{\circ} \mathrm{C}$ in the salt chamber, humidification temperature of $50{ }^{\circ} \mathrm{C}$ ) and pressure of 1 bar were reached.

6. When the chamber was switched off, key shift with zero position was switched to ventilation. During measurement it was controlled if the jet works correctly. If the jet is clogged, it has to be cleaned. It is also necessary to control the amount 
of created condensate: $1-2 \mathrm{ml}$ of condensate on the surface of $80 \mathrm{~cm}^{2}$ should be created within 1 hour of the test and $\mathrm{pH}$ of the condensate should be between 6,5 and 7,2 .

\subsection{Processing of results}

1. Corroding was measured in the following way: self-adhesive tape was stuck along the cut after drying out at laboratory temperature 24 hours after the chamber was switched off.

2. The tape was smoothed at the point of surface cut at least in the distance of $20 \mathrm{~mm}$ behind every cut end. The tape was toughly pressed by fingertips. It was removed within 5 minutes, seized for free end and gradually took off for $0,5-1 \mathrm{~s}$ approximately $60^{\circ}$ angle-wise to the tested sample.

\section{Obtained results and their discussion}

\subsection{Setting up the corrosion test by salt spray and principle of the method}

Measurements of corrosion of plastic-coated samples in salt spray was carried out at U. S. Steel Košice - Labortest Ltd. in a testing laboratory of the Cold rolling mill. Measurement results are recorded in Table 2. Measured data were subsequently statistically processed.

Table 2.Measured values obtained from the experiment.

\begin{tabular}{|c|c|c|c|c|c|c|}
\hline \multicolumn{7}{|c|}{ Sample identification: zinc coated sheet with organic coating } \\
\hline \multicolumn{7}{|c|}{ Required tests: norm used: corrosion test in salt spray (STN ISO 9227) } \\
\hline $\begin{array}{l}\text { Exp. } \\
\text { No. }\end{array}$ & $\begin{array}{l}\text { Std } \\
\text { Ord. }\end{array}$ & Blocks & $\begin{array}{l}\mathrm{Zn}- \\
\text { layer } \\
{[\mu \mathrm{m}]}\end{array}$ & $\begin{array}{c}\text { Top+ } \\
\text { primer } \\
{[\mu \mathrm{m}]}\end{array}$ & $\begin{array}{c}\text { Backoat } \\
{[\mu \mathrm{m}]}\end{array}$ & $\begin{array}{l}\text { Corroding } \\
\text { Time } \\
\text { [hrs] }\end{array}$ \\
\hline 1 & 7 & 1 & 139 & 25 & 10 & 1128 \\
\hline 2 & 5 & 1 & 139 & 5 & 10 & 480 \\
\hline 3 & 11 & 1 & 139 & 25 & 7 & 1128 \\
\hline 4 & 16 & 1 & 144 & 25 & 10 & 1128 \\
\hline 5 & 6 & 1 & 144 & 5 & 10 & 480 \\
\hline 6 & 12 & 1 & 144 & 25 & 7 & 888 \\
\hline 7 & 14 & 1 & 144 & 5 & 10 & 312 \\
\hline 8 & 13 & 1 & 139 & 5 & 10 & 384 \\
\hline 9 & 10 & 1 & 144 & 5 & 7 & 312 \\
\hline 10 & 9 & 1 & 139 & 5 & 7 & 384 \\
\hline 11 & 15 & 1 & 139 & 25 & 10 & 888 \\
\hline 12 & 4 & 1 & 144 & 25 & 7 & 888 \\
\hline 13 & 2 & 1 & 144 & 5 & 7 & 312 \\
\hline 14 & 3 & 1 & 139 & 25 & 7 & 1128 \\
\hline 15 & 1 & 1 & 139 & 5 & 7 & 480 \\
\hline 16 & 8 & 1 & 144 & 25 & 10 & 888 \\
\hline
\end{tabular}

Software package Minitab 16 was used for statistical processing of results. In order to process measured results, full factorial design with 3 factors and 2 levels was 
created. It means that number of measurements should be $2^{3}$. Since there are not any central points, the number of blocks is 1 , the number of repeated measurements (for 8 coils - samples) at all non-central points of experimental plan is 2 , so the entire number of measurements was $2 \times 2^{3}$, i.e. 16 . Randomization of experiment was created in order not to allow the influence of previous and following measurements. The analysis of factorial design in linear model, which includes elements up to degree 2 (element up to degree 3 presents scratch and was not taken into consideration), was carried out. Selected factors are indicated in the following way: factor A - Zn-layer, factor B - Top+primer, factor C - Backoat and interactions of factors A.B, A.C, B.C.Tables of factorial regression - Table 3, where analysis of variance for linear model was carried out and Table 4, where significance of factors and interactions is inscribed, were obtained at analysis of full factorial design. Software Minitab 16 creates considerable number of charts at analysis of factorial design. Pareto Chart of the Standardized Effects and Normal Plot of the Standardized Effects, which provide us sufficient amount of information about the influence of factors or their interactions on response, were chosen.

Table 3.Factorial regression: Corroding time on $\mathrm{Zn}$-layer, Top+primer, Backoat.

\begin{tabular}{|c|c|c|c|c|c|c|}
\hline \multicolumn{7}{|c|}{ Analysis of Variance } \\
\hline Source & & DF & Adj SS & Adj MS & F-Value & P-Value \\
\hline Model & & 6 & 1583640 & 263940 & 27,30 & 0,000 \\
\hline Linear & & 3 & 1553868 & 517956 & 53,57 & 0,000 \\
\hline \multicolumn{2}{|c|}{ zn-layer } & 1 & 39204 & 39204 & 4,06 & 0,075 \\
\hline Top+primer & 1 & 151 & $2900 \quad 151$ & $2900 \quad 15$ & 56,49 & 0,000 \\
\hline Backoat & 1 & & 1764 & 1764 & 0,18 & 0,679 \\
\hline \multicolumn{7}{|c|}{ 2-Way Interactions } \\
\hline & & 3 & 29772 & 9924 & 1,03 & 0,426 \\
\hline \multicolumn{7}{|c|}{ Zn-layer*Top+primer } \\
\hline & & 1 & 1764 & 1764 & 0,18 & 0,679 \\
\hline \multicolumn{7}{|c|}{ Zn-layer*Backoat } \\
\hline & & 1 & 26244 & 26244 & 2,71 & 0,134 \\
\hline \multicolumn{7}{|c|}{ Top+primer*Backoat } \\
\hline & & 1 & 1764 & 1764 & 0,18 & 0,679 \\
\hline \multicolumn{2}{|c|}{ Lack-of-Fit } & 1 & 6084 & 6084 & 0,60 & 0,460 \\
\hline Pure $\mathbf{E}$ & ror & 8 & 80928 & 10116 & & \\
\hline Total & & 15 & 1670652 & & & \\
\hline
\end{tabular}

Table 4.Significance of factors and interactions.

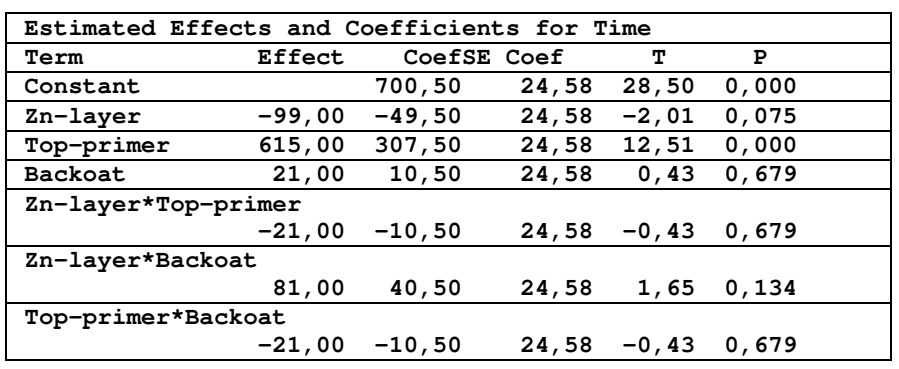


Effect of factors or interaction of factors - response on change of the factor from value -1 to value 1 is calculated in the first column of Table 4 . Regression coefficient can be found in the second column, which is a half of effect of factors or interaction of factors. Statistical significance of factor or interaction expressed by $p$ can be found in the fifth column. The closer the value $p$ of factor or interaction of factors to zero, the more statistically significant factor or interaction of factors. Table with calculated effects and coefficients serves us as a source of information in order to create mathematical model, which would have the following shape [8]. Regression equation (1):

Corroding time $=700,5-49,5 \cdot \mathrm{A}+307,5 \cdot \mathrm{B}+10,5 \cdot \mathrm{C}-10,5 \cdot \mathrm{A} \cdot \mathrm{B}+40,5 \cdot \mathrm{A} \cdot \mathrm{C}-10,5 \cdot \mathrm{B} \cdot \mathrm{C}$

where selected factors are indicated as it follows: factor A - Zn-layer, factor B Top+primer, factor C - Backoat and interactions of factors A.B, A.C, B.C.

The next step is to separate "significant" factors or interactions from those that create only experimental scratch. Pareto Chart of the Standardized Effects and Normal Plot of the Standardized Effects are used for that. It is possible to conclude that only factor B - Top+primer would have real influence on corroding time, when corrosion occurs (Figure 4).

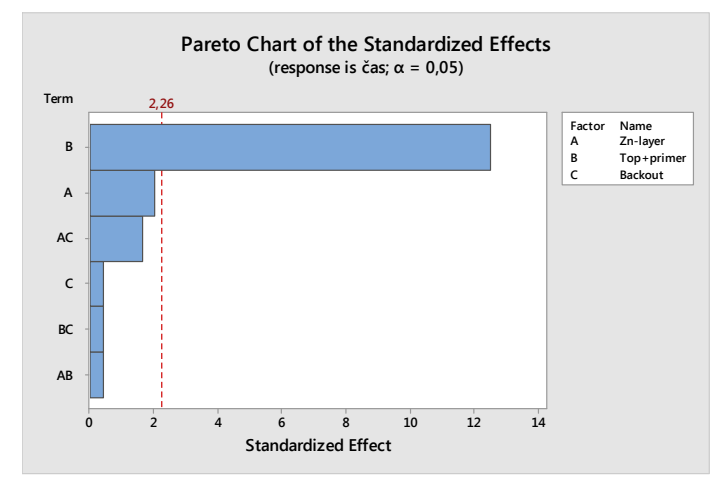

Fig. 4.Pareto Chart of the Standardized Effects

For interaction of B.C factors, the influence on corroding time will be higher at upper level of B factor - Top-primer and it can be raised by change of $\mathrm{C}$ factor Backoat on lower level. For interaction of A.B factors, the influence on corroding time is the same as at A factor - Zn-layer, but it is influenced by upper level of B factor - Top-primer. Finally, for interaction of A.C factors, corroding time is predominantly influenced by lower level of A factor - Zn-layer and it can be raised by lower level of $\mathrm{C}$ factor - Backoat (Figure 5). 


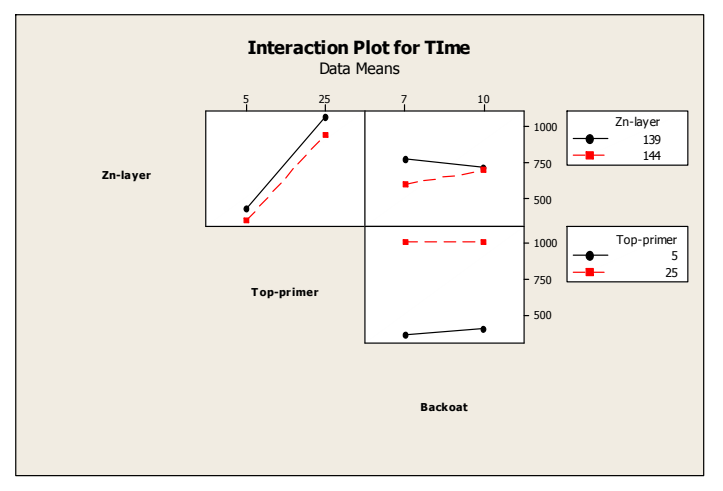

Fig. 5. Influence of interaction of factors on corroding time.

It is obvious from Figure 6 that if interactions between the factors are neglected, B - Top-primer and its setting to the upper level has the biggest influence on corroding time from all the factors. It is followed by A factor - Zn-layer, which is set to the lower level. Finally, it is C factor - Backoat, which is set to the upper level.

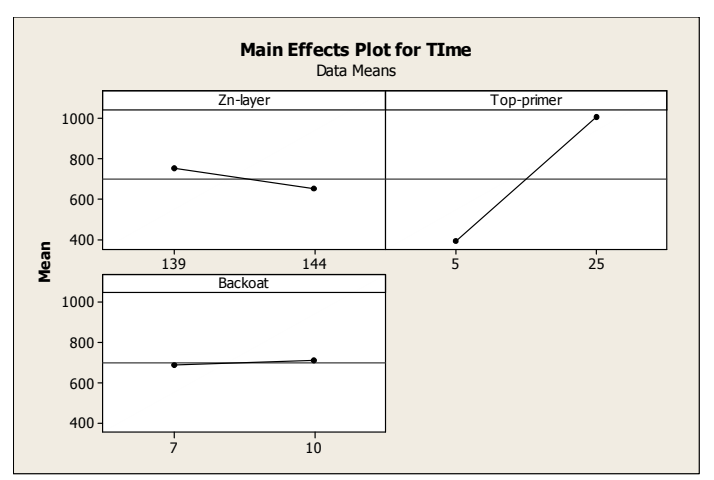

Fig. 6. Influence of individual factors on corroding time.

Points of effects of factors or interactions are described in the Normal Plot of the Standardized Effects (Figure 7) and separated by a straight line. The points, which lie on the straight line, belong to scratch. The points, which lie beyond the straight line, belong to "real" factors. It is in accordance with the result obtained from Pareto Chart (Figure 4).

Three-dimensional Surface Plot, which displays shiny surface lighted from a suitable angle, provides even more demonstrative visualization of corroding time dependence on Top+primer and Backout at Zn-layer of $139 \mu \mathrm{m}$ (Figure 8). From this figure it is obvious that maximum value for parameter of corroding time is reached for Top+primer of $25 \mu \mathrm{m}$ and Backoat of $7 \mu \mathrm{m}$ and minimum value for corroding time is reached for Top+primer of $5 \mu \mathrm{m}$ and Backaot of $10 \mu \mathrm{m}$. This display is available from Minitab16 - 3D graph tools program package. 


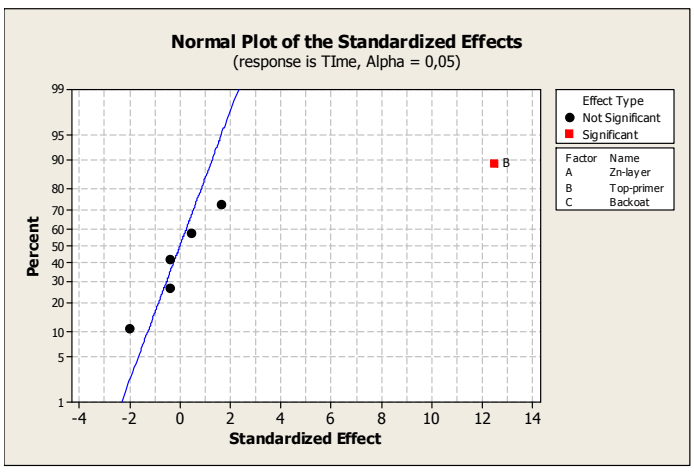

Fig. 7.Normal Plot of the Standardized Effects.

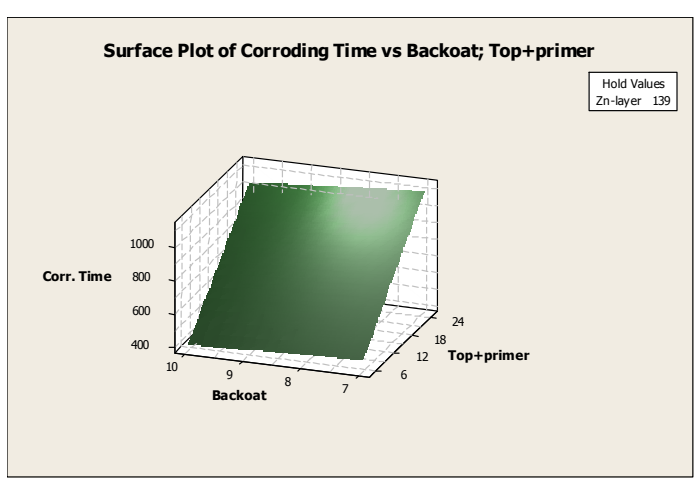

Fig. 8. Surface Plot of Corrosion Time vs Backoat.

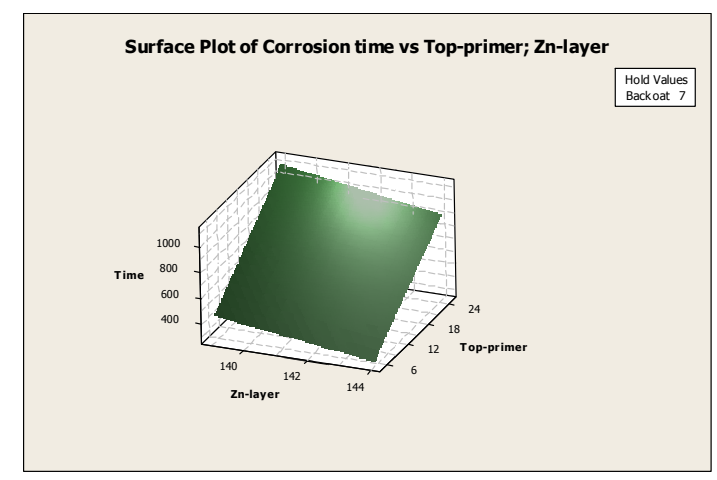

Fig. 9.Surface plot of Corrosion Time vs Top+primer.

As it results from Figure 9, quite high value of corroding time can be observed at Top+primer $25 \mu \mathrm{m}$ and Zn-layer $139 \mu \mathrm{m}$ and hold value of Backout $7 \mu \mathrm{m}$. 
Minimum value for corroding time is reached for Top+primer of $5 \mu \mathrm{m}$ and $\mathrm{Zn}$-layer of $144 \mu \mathrm{m}$.

Finally, as it results from Figure 10 at hold value of Top-primer $5 \mu \mathrm{m}$, the maximum value of corroding time is 450 hours at Z-layer $139 \mu \mathrm{m}$ and backoat $7 \mu \mathrm{m}$, which is not a half of value of corroding time at combinations of observed layers resulting from Figure 8 and Figure 9. Minimum value of corroding time is 300 hours at $\mathrm{Zn}$ layer $144 \mu \mathrm{m}$ and Backoat $7 \mu \mathrm{m}$.

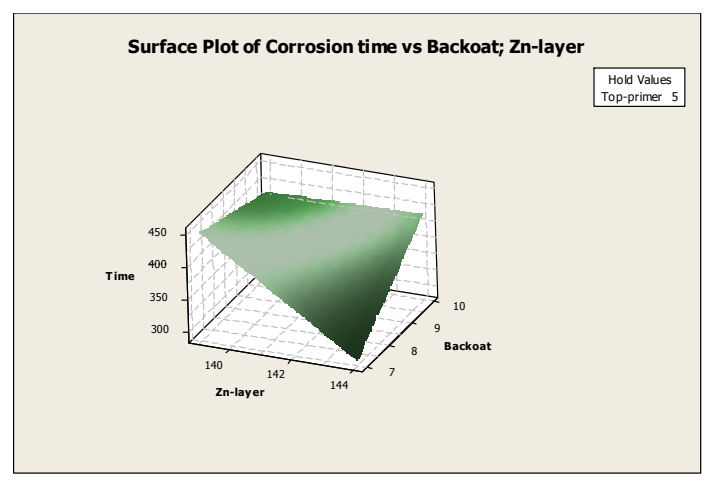

Fig.10. Surface plot of Corrosion Time vs Backkoat.

\section{Conclusion}

Experiments were designed according to standard full factorial design to find out relations and creation of mathematical models between factors A - Zn-layer, B - Top+primer, C - Backcout and observed response - corroding time. Pareto Chart of the Standardized Effects and Normal probability were used to evaluate the influence of input factors on observed response.

Based on experimental results and their statistical behaviour the following conclusions can be defined:

1. Top+primer coating $[\mu \mathrm{m}]$ compared to Zn-layer $[\mu \mathrm{m}]$ and Backout $[\mu \mathrm{m}]$ has the most significant influence on observed response of corroding time. Although factors of $\mathrm{Zn}$-layer and Backaot have the lower influence on corroding time, if they are compared to each other, Zn-layer has the higher influence, particularly its lower level (Figure 6).

2. If interaction of $\mathbf{B} \cdot \mathrm{C}$ factors is taken into consideration, the influence on corroding time will be higher at the upper level of $\mathrm{B}$ factor - Top-primer and it can be raised by the change of $\mathrm{C}$ factor - Backoat on lower level. For interaction of $\mathrm{A} \cdot \mathrm{B}$ factors, the influence on corroding time is the same as at A factor, but it is influenced by the upper level of B factor. Finally, for interaction of A.C factors, corroding time is mostly influenced by the lower level of A factor - Zn-layer and it can be raised by the lower level of $\mathrm{C}$ factor - Backoat (Figure 5). 
3. Three-dimensional surface plot (Figure 8, Figure 9, Figure 10) allows us to gain information on values of corroding time. Maximum value of corroding time is reached for Top+primer of $25 \mu \mathrm{m}$ and Backoat of $7 \mu \mathrm{m}$ at hold value of $\mathrm{Zn}$-layer $139 \mu \mathrm{m}$ (Figure 8). High value of corroding time also occurs at Top+primer $25 \mu \mathrm{m}$ and Zn-layer $139 \mu \mathrm{m}$ and hold value of Backout $7 \mu \mathrm{m}$ (Figure 9), while almost half value of corroding time can be observed at Zn-layer $139 \mu \mathrm{m}$ and backoat $7 \mu \mathrm{m}$ a hold value of Top-primer $5 \mu \mathrm{m}$ (Figure 10).

\section{References}

[1] Oppelt, J., Blahetová, M., Lasek, S., Cíhal, V. Mechanics, Vol. 298, Politech. Opolska (2005)

[2] Černý, M. et al. Corrosion properties of metal construction materials. Praha, SNTL, (1984)

[3] Billy, J., Gašpar, V., Vargová, V., Pallagová, A., Vida, S. Zinc dipping of tensile newly designed IF construction and microalloyed steels. Final report of the partial task of research project, Licence No. P 5-12/3, pp. 61, October (1996)

[4] Tarhanicová, R. Metallographic analysis of organic-coated steels. Expertise No. MOP 99/08, February (2008)

[5] Tarhanicová, R. Metallographic analysis of organic-coated steels - white corrosion formation. Expertise No. MOP 606/05, December (2005)

[6] Technical letter: Selection of the right plastic coated product, October 2015, ECCA CEE Slovakia National Group

[7] STN EN ISO 9227: 2012 (03 8132). Corrosion tests in artificial atmospheres - Salt spray tests (ISO 9227: 2012)

[8] Miller, I. DOE - Design and analysis of experiment by means of MINITAB. INTERQUALITY, spol s r. o., Praha, ISBN 9788090277052, (2010). 